\title{
POST-OPERATIVE ASTIGMATISM CONTROL BY SELECTIVE SUTURE REMOVAL
}

\author{
AMANDA J. CHURCHILL and JEFFREY S. HILLMAN \\ Leeds
}

\begin{abstract}
SUMMARY
Fifty eyes in 50 patients with $>2.5$ dioptres (D) of withthe-rule astigmatism (refraction) following uncomplicated extracapsular cataract extraction were recruited for this prospective study. Selected single sutures were removed and both the amount of astigmatic loss and the change in axis were measured at intervals. After removal of the first suture the mean astigmatic loss at 1 week was $2.9 \mathrm{D}$ by keratometry and the mean change in the axis was $23^{\circ}(74 \%$ occurred within the first hour). The astigmatic loss was greater with subsequent suture removal. Timing of suture removal (before or after 8 weeks) and the amount of initial post-operative astigmatism (more than or less than $5 \mathrm{D}$ ) had a minimal effect on the total astigmatic loss. We suggest selective single suture removal can be performed safely at 5-6 weeks post-operatively with removal of a second suture, if necessary, in the steepest axis after 1 hour. The prescription of spectacles should be delayed for 1 week after the final suture has been removed.
\end{abstract}

The intraocular lens gives the patient a high quality of vision after cataract surgery and the calculation of intraocular lens power for each individual eye from careful biometry data allows the surgeon to control post-operative refraction within narrow limits. High levels of post-operative corneal astigmatism increase the cylindrical spectacle correction required and, especially when irregular, can reduce the quality of both corrected and uncorrected vision. The amount of post-operative astigmatism is related to the length and position of the wound incision and to the position and tension of the sutures. In the long term there is some gradual natural decay of corneal astigmatism but this does not remove all astigmatism, and certainly in the short term astigmatism can delay the visual rehabilitation of the patient after surgery. This study was undertaken to investigate the effect on both the amount and axis of post-operative

Correspondence to: Amanda J. Churchill, FRCOphth, Department of Ophthalmology, St James's University Hospital, Leeds LS9 7TF, UK. astigmatism of cutting selected single sutures following cataract surgery and to establish a protocol for suture management.

\section{MATERIALS AND METHODS}

This study was undertaken on 50 eyes in 50 patients following uncomplicated extracapsular cataract extraction which had resulted in 2.5 dioptres (D) or more of with-the-rule astigmatism on manual refraction. The range was $2.5-12.0 \mathrm{D}$. In all cases posterior corneal incisions were used and between four and six interrupted 10-0 nylon sutures placed to establish satisfactory wound closure.

Suture cutting was commenced in the majority of cases between weeks 5 and 8 post-operatively (range 5-25 weeks). Prior to suture removal the eye was refracted manually and keratometry recorded using the Canon Auto Keratometer. A single suture was cut in the axis of the steepest meridian (axis of the plus cylinder) at the slit lamp using a 21 gauge needle following benoxinate topical anaesthesia.

Keratometry was recorded at 30 minutes, 60 minutes and 1 week after suture removal. A manual refraction was carried out after 1 week. At that stage, if astigmatism still amounted to $2.5 \mathrm{D}$ or more, a further suture was cut following the same protocol and this was continued a third and fourth time if necessary on the basis of residual astigmatism. The results were analysed to investigate the pattern of decay of astigmatism following suture removal, with the aim of defining a protocol for this technique for the management of post-operative astigmatism.

\section{RESULTS}

Due to occasional missing data the numbers in the tables do not always add up to 50 eyes.

Thirty minutes after removing the first suture a mean astigmatic loss of $1.63 \mathrm{D}$ was measured by keratometry. This value varied between $2.19 \mathrm{D}$ and $3.16 \mathrm{D}$ after removal of the second, third and fourth sutures. The rate of loss was greatest during the first 
Table I. Mean astigmatic change following suture removal at 30 minutes, 60 minutes and 1 week measured by keratometry and the mean total astigmatic change over 1 week measured by refraction

\begin{tabular}{|c|c|c|c|c|}
\hline & First suture & Second suture & Third suture & Fourth suture \\
\hline Mean $\mathrm{K}$ value ast. change (D) $0-30 \mathrm{~min}$ & $\begin{array}{r}1.63 \\
(56 \%)\end{array}$ & $\begin{array}{c}2.19 \\
(64 \%)\end{array}$ & $\begin{array}{r}2.85 \\
(70 \%)\end{array}$ & $\begin{array}{r}3.16 \\
(78 \%)\end{array}$ \\
\hline Mean $\mathrm{K}$ value ast. change (D) $30-60 \mathrm{~min}$ & $\begin{array}{r}0.54 \\
(18 \%)\end{array}$ & $\begin{array}{r}0.42 \\
(12 \%)\end{array}$ & $\begin{array}{r}0.56 \\
(14 \%)\end{array}$ & $\begin{array}{c}0.22 \\
(5 \%)\end{array}$ \\
\hline Mean $\mathrm{K}$ value ast. change (D) $60 \mathrm{~min}$ to 1 week & $\begin{array}{c}0.77 \\
(26 \%)\end{array}$ & $\begin{array}{c}0.84 \\
(24 \%)\end{array}$ & $\begin{array}{r}0.67 \\
(16 \%)\end{array}$ & $\begin{array}{r}0.70 \\
(17 \%)\end{array}$ \\
\hline Mean $K$ value ast. change (D) over 1 week & 2.94 & 3.45 & 4.08 & 4.08 \\
\hline Mean refraction ast. change (D) over 1 week & 1.82 & 1.58 & 1.25 & 1.90 \\
\hline Total no. of patients & 50 & 26 & 9 & 4 \\
\hline
\end{tabular}

ast., astigmatic.

30 minutes compared with that measured in the other two time periods (Table I). The figures in brackets in Table I refer to the percentage of the total mean astigmatic loss measured after 1 week.

From these results we can calculate that 1 week after removal of the first suture the mean change in astigmatism was $2.9 \mathrm{D}$ by keratometry and $1.8 \mathrm{D}$ by refraction. Fifty-six per cent occurred within the first 30 minutes and $74 \%$ within the first hour. Removal of subsequent sutures affected the keratometry values to a greater degree than the manual refraction, the latter giving a mean astigmatic loss ranging from 1.25 to $1.90 \mathrm{D}$ for each suture removed (Table I).

The mean change in the axis of astigmatism over 1 week after the first suture was removed was $23^{\circ}$ and $24^{\circ}$ by keratometry and refraction respectively. Fiftyseven per cent of this change occurred within the first 30 minutes and $74 \%$ within the first hour (Table II).

The mean coupled steepening of the opposite meridian to that in which the suture was cut was $1.2 \mathrm{D}$ when measured by both the change in keratometry and refraction (Table III).

The effect of removal of second, third and fourth sutures is similarly presented in Tables I-III.

To determine whether the initial amount of postoperative astigmatism influenced the decay in astigmatism following single suture removal, comparison was made between eyes with $<5 \mathrm{D}$ post-operative astigmatism ( 24 eyes) and those with $>5 \mathrm{D}$ (24 eyes).
The results are presented in Table IV. From the mean keratometry values it was observed that the group with the higher initial astigmatism lost $79 \%$ total astigmatic loss within the first hour compared with $69 \%$ in the group with the lower amount of initial astigmatism. After 1 week the difference in overall mean astigmatic loss between the two groups was $0.3 \mathrm{D}$.

The two groups above were further subdivided according to the timing of first suture removal (before or after 8 weeks post-operatively) to determine whether this influenced the rate of change of astigmatism. There appeared to be very little difference between the groups in either the amount of astigmatic loss or the rate at which this was achieved (Table V). It should be noted, however, that the number of eyes having the first suture removed after 8 weeks was small $(n=7)$.

\section{DISCUSSION}

Patients demand and expect rapid visual rehabilitation following uncomplicated cataract surgery. We regard it as unacceptable to leave patients with large amounts of with-the-rule astigmatism without modifying it by the simple technique of selective suture removal. As a profession we must be aware of the increasing expectations of our patients and the ease with which litigation can be processed.

Surgical technique must be aimed at minimising post-operative astigmatism. The more corneal and

Table II. Mean axis change following suture removal at 30 minutes, 60 minutes and 1 week measured by keratometry and the mean total axis change over 1 week measured by refraction

\begin{tabular}{|c|c|c|c|c|}
\hline & First suture & Second suture & Third suture & Fourth suture \\
\hline Mean $\mathrm{K}$ value ast. axis change (D) $0-30 \mathrm{~min}(\mathrm{deg})$ & $\begin{array}{l}13 \\
(57 \%)\end{array}$ & $\begin{array}{l}17 \\
(47 \%)\end{array}$ & $\begin{array}{l}37 \\
(71 \%)\end{array}$ & $\begin{array}{l}27 \\
(54 \%)\end{array}$ \\
\hline Mean $\mathrm{K}$ value ast. axis change $30-60 \mathrm{~min}(\mathrm{deg})$ & $\begin{array}{c}4 \\
(17 \%)\end{array}$ & $\begin{array}{c}5 \\
(14 \%)\end{array}$ & $\begin{array}{c}4 \\
(8 \%)\end{array}$ & $\begin{array}{c}4 \\
(8 \%)\end{array}$ \\
\hline Mean $\mathrm{K}$ value ast. axis change $60 \mathrm{~min}$ to 1 week (deg) & $\begin{array}{c}6 \\
(26 \%)\end{array}$ & $\begin{array}{c}14 \\
(39 \%)\end{array}$ & $\begin{array}{c}11 \\
(21 \%)\end{array}$ & $\begin{array}{c}19 \\
(38 \%)\end{array}$ \\
\hline Mean $\mathrm{K}$ value ast. axis change over 1 week (deg) & 23 & 36 & 52 & 50 \\
\hline Mean refraction ast. axis change in 1 week (deg) & 24 & 23 & 47 & 70 \\
\hline Total no. of patients & 48 & 27 & 9 & 5 \\
\hline
\end{tabular}

ast., astigmatic. 
Table III. Mean coupled steepening of the meridian opposite to that in which the suture was cut, measured by keratometry and refraction

\begin{tabular}{lcccc}
\hline & \multicolumn{3}{c}{ Mean coupled steepening of opposite meridian at 1 week (D) } \\
\cline { 2 - 5 } & First suture & Second suture & Third suture & Fourth suture \\
\hline Keratometry (change in the flattest meridian) & 1.21 & 1.17 & 1.24 & 1.54 \\
Refraction (change in the sphere) & 1.20 & 1.14 & 0.82 & 1.50 \\
Total no. of patients & 49 & 26 & 10 & 5 \\
\hline
\end{tabular}

the longer the incision, the greater the tendency for induced astigmatism. Sutures which are irregularly spaced, non-radial or of uneven or excessive tension also tend to induce astigmatism which often proves on corneal topographical analysis to be irregular in type.

There is a slow natural decay of post-operative astigmatism which is well demonstrated by the study by Talamo et al. ${ }^{1}$ Mean post-operative keratometry values of $1.44 \mathrm{D}$ (with-the-rule) astigmatism reduced over 48 months to a maximum value of $1.23 \mathrm{D}$ against the rule. They suggested that suture removal was necessary only when more than $3.0 \mathrm{D}$ of withthe-rule astigmatism (by keratometry) was present. ${ }^{1}$ More recently Drews ${ }^{2}$ has shown that in 25 patients there was a mean shift of astigmatism of greater than 3.0 D against the rule 5 years following uncomplicated cataract surgery (without suture removal).

This study was designed to investigate the effect on both the amount of post-operative astigmatism and the change in axis of cutting selected single sutures in eyes with $>2.5 \mathrm{D}$ with-the-rule astigmatism by refraction. From our results we found that refraction values equated to approximately $50 \%$ of the keratometry values, so $2.5 \mathrm{D}$ by refraction equated to $5.0 \mathrm{D}$ by keratometry. The lower limit of $2.5 \mathrm{D}$ by refraction was chosen to avoid the danger of creating significant against-the-rule astigmatism.

Kronish and Forster ${ }^{3}$ demonstrated that a reduction of $1.2 \mathrm{D}$ astigmatism (by keratometry) was achieved for each suture removed, and suggested a regime whereby more sutures could be cut at one sitting according to the desired reduction of astigmatism. In the present study a mean reduction in astigmatism of $2.94 \mathrm{D}$ (keratometry) or $1.82 \mathrm{D}$

Table IV. A comparison of two groups to show the effect of the size of initial astigmatism on the astigmatic loss achieved after removal of suture

\begin{tabular}{lcc}
\hline & \multicolumn{2}{c}{ Mean K value astigmatic change (D) } \\
\cline { 2 - 3 } $\begin{array}{l}\text { Time after first suture } \\
\text { removed }\end{array}$ & $\begin{array}{c}<5 \text { astigmatism } \\
\text { post-op. }(n=24) \\
(\% \text { total }) \\
\text { astigmatic loss) }\end{array}$ & $\begin{array}{c}>5 \text { D astigmatism } \\
\text { post-op. }(n=24) \\
(\% \text { total } \\
\text { astigmatic loss })\end{array}$ \\
\hline 0-30 min & $1.39(50 \%)$ & $1.88(61 \%)$ \\
30-60 min & $0.52(19 \%)$ & $0.56(18 \%)$ \\
60 min to 1 week & $0.87(31 \%)$ & $0.64(21 \%)$ \\
$\begin{array}{l}\text { Total astigmatic loss } \\
\text { in 1 week }\end{array}$ & 2.78 & 3.08 \\
\hline
\end{tabular}

(refraction) was achieved by removal of the first suture (Table I) and a mean coupled steepening of 1.2 $\mathrm{D}$ in the opposite meridian (Table III). Removal of a second suture gave a further mean reduction of $3.45 \mathrm{D}$ by keratometry, and removal of third and fourth sutures achieved a loss of $4.08 \mathrm{D}$ by keratometry. The overall reduction in astigmatism seen at 1 week appears to remain relatively stable on refraction, ranging from $1.25 \mathrm{D}$ to $1.9 \mathrm{D}$. The rate of loss, however, is faster with the second, third and fourth sutures, with up to $84 \%$ (third suture) occurring in the first hour compared with only $76 \%$ after the first suture was removed (Table I).

Analysis of Table IV suggests, as might be expected, that the higher the initial post-operative astigmatism the greater will be the overall effect of removal of a single suture. Using the standard error of the means for statistical analysis we found that the difference in the amount of astigmatic change in the two groups over the first 30 minutes and that over the first hour was not significant $(0.317>p>0.1$ for both comparisons).

The difference in effect of the timing of suture removal between the groups exhibiting $<5 \mathrm{D}$ and $>5 \mathrm{D}$ astigmatism was most noticeable in the initial stages when the first suture was removed $<8$ weeks following surgery: $42 \%$ astigmatic loss measured over 1 week occurred in the first 30 minutes in the $<5 \mathrm{D}$ astigmatism group compared with $64 \%$ in the $>5 \mathrm{D}$ group (Table $\mathrm{V}$ ). Using the standard error of the means for statistical analysis we found that this difference was significant $(0.046>p>0.01)$, although by 1 hour the margin had lessened. The numbers in the $>8$ week groups are too small for useful statistical analysis, but suture removal at a later stage does appear to give a smaller reduction in post-operative astigmatism. We recommend initial single suture removal at 5-6 weeks following surgery. No wound leakage was demonstrated in any of the patients in this study, but this risk cannot be entirely excluded, especially with very tight sutures which delay healing.

The use of interrupted 10-0 nylon sutures for corneal wound closure has been shown to give a high degree of with-the-rule post-operative astigmatism, but the incidence of complications such as iris prolapse is less than that seen with 9-0 polypropylene. ${ }^{4}$ An earlier study comparing the induced postoperative astigmatism with interrupted versus 
Table V. The effect of timing of suture removal on the rate and degree of astigmatic loss

\begin{tabular}{|c|c|c|c|c|}
\hline \multirow[b]{3}{*}{$\begin{array}{l}\text { Time after first } \\
\text { suture removed }\end{array}$} & \multicolumn{4}{|c|}{ Mean $\mathrm{K}$ value astigmatic change (D) } \\
\hline & \multicolumn{2}{|c|}{$\begin{array}{l}\text { First suture removed }<8 / 52 \\
\text { post-op. (range } 5-8 \text { weeks) }\end{array}$} & \multicolumn{2}{|c|}{$\begin{array}{l}\text { First suture removed }>8 / 52 \\
\text { post-op. (range } 11-25 \text { weeks) }\end{array}$} \\
\hline & $\begin{array}{c}<5 \mathrm{D} \text { astigmatism } \\
(n=17)\end{array}$ & $\begin{array}{c}>5 \mathrm{D} \text { astigmatism } \\
\quad(n=21)\end{array}$ & $\begin{array}{c}<5 \mathrm{D} \text { astigmatism } \\
(n=4)\end{array}$ & $\begin{array}{c}>5 \mathrm{D} \text { astigmatism } \\
(n=3)\end{array}$ \\
\hline $\begin{array}{l}0-30 \mathrm{~min} \\
30-60 \mathrm{~min} \\
60 \mathrm{~min} \text { to } 1 \text { week }\end{array}$ & $\begin{array}{l}1.15(42 \%) \\
0.68(25 \%) \\
0.91(33 \%)\end{array}$ & $\begin{array}{l}1.97(64 \%) \\
0.46(15 \%) \\
0.65(21 \%)\end{array}$ & $\begin{array}{c}1.51(63 \%) \\
0.18(8 \%) \\
0.69(29 \%)\end{array}$ & $\begin{array}{l}1.2(40 \%) \\
1.2(40 \%) \\
0.6(20 \%)\end{array}$ \\
\hline Total astigmatic loss in 1 week & 2.74 & 3.08 & 2.38 & 3.00 \\
\hline
\end{tabular}

continuous 10-0 nylon showed no significant difference between the methods. ${ }^{5}$ We prefer the use of interrupted sutures because we feel that control of post-operative astigmatism can be achieved more easily and safely than by adjusting the tension of a continuous suture. Where continuous sutures are used, a recent study suggests that the optimum time for removal is 12 weeks following surgery. ${ }^{6}$ However, it is difficult to predict accurately the astigmatic effect of removal of a continuous suture or all interrupted sutures at one sitting.

Kronish and Forster ${ }^{3}$ found that it took 4 weeks of natural decay to achieve $75-93 \%$ astigmatic stability following suture removal, and that the final astigmatism recorded 1 year after surgery increased by a mean of $0.9 \mathrm{D}$ (predominantly with the rule). Baranyovits ${ }^{7}$ suggested that prescription of spectacles should be withheld for 3 months following surgery. Parker and Clorfeine ${ }^{8}$ however, found that the 3 month refraction was not stable and that there was a gradual shift of $0.69 \mathrm{D}$ astigmatism against the rule over a 3 year follow-up after all sutures had been removed. It could be argued that prescription of spectacles should be withheld until successive refractions indicate stability, but patients, quite reasonably, demand a more rapid result. We feel a safe compromise can be achieved. As $74 \%$ of the mean astigmatic and axis change in 1 week occurred in the first hour following removal of the first suture, and the mean axis change from 1 hour to 1 week amounted to only $6^{\circ}$ (Table II), it would seem reasonable to extrapolate these data and allow removal of a second suture in the new steepest axis after 1 hour. We do not feel that routine removal of all sutures at 12 weeks, as suggested in a recent study, is justified because we have demonstrated that there can be a significant change in astigmatism by suture removal as late as 25 weeks following surgery. ${ }^{9} \mathrm{We}$ also feel that the prescription of spectacles should be delayed for 1 week after final suture removal. This not only allows rapid visual rehabilitation for the patient, but enables the ophthalmologist to ensure that the residual astigmatism is sufficiently small for spectacles to be prescribed. The patient can then be confidently discharged back to their regular optometrist.

Key words: Astigmatism, Cataract, Sutures.

\section{REFERENCES}

1. Talamo JH, et al. Natural history of corneal astigmatism after cataract surgery. J Cataract Refract Surg 1991; 17:313-8.

2. Drews RC. Astigmatism after cataract surgery: Nylon versus Mersilene. Five-year data. J Cataract Refract Surg 1995;21:70-2.

3. Kronish JW, Forster RK. Control of corneal astigmatism following cataract extraction by selective suture cutting. Arch Ophthalmol 1987;105:1650-5.

4. Driscoll AM, et al. A prospective, controlled study of a 9-0 elastic polypropylene suture for cataract surgery: refractive results and complications. Eye 1994;8:538-42.

5. Stainer GA, et al. The natural and modified course of post-cataract astigmatism. Ophthalmic Surg 1982; 13:822-7.

6. Stanford MR, Fenech T, Hunter PA. Timing of removal of sutures in control of post-operative astigmatism. Eye 1993;7:143-7.

7. Baranyovits P. Stabilisation of refraction following extracapsular cataract extraction. $\mathrm{Br} \mathbf{J}$ Ophthalmol 1990;74:486-9.

8. Parker WT, Clorfeine GS. Long-term evolution of astigmatism following planned extracapsular cataract extraction. Arch Ophthalmol 1989;107:353-7.

9. Danjoux JP, Reck AC. Corneal sutures: Is routine removal really necessary? Eye 1994;8:339-42. 